\title{
Improved optical and electrical properties of low-temperature sputtered GaN by hydrogenation
}

\author{
E. C. Knox-Davies, S. J. Henley, ${ }^{\text {a) }}$ J. M. Shannon, and S. R. P. Silva ${ }^{\text {b) }}$ \\ Advanced Technology Institute, University of Surrey, Guildford, Surrey GU2 7XH, United Kingdom
}

(Received 15 August 2005; accepted 28 December 2005; published online 14 February 2006)

\begin{abstract}
The room-temperature photoluminescence intensity and conductivity of GaN films grown by reactive rf sputtering were improved by the addition of hydrogen during growth. The differential resistivity decreased by two orders of magnitude when $2.4 \% \mathrm{H}_{2}$ was added to the deposition gas. The improvement in the photoluminescence intensity occurred together with an increase in the level of oxygen contamination and an apparent increase in the structural disorder. At 0 and $20 \% \mathrm{H}_{2}$, respectively, the refractive indices were 2.45 and 1.98, and the bandgaps were 3.06 and $3.64 \mathrm{eV}$, with the change attributed to oxygenation. (C) 2006 American Institute of Physics.

[DOI: $10.1063 / 1.2171780]$
\end{abstract}

There have been a significant number of reports of GaN grown at low temperatures, but the majority of these have not been of sufficient quality to be used in technologically useful devices. Most of the reports have used rf sputtering of Ga or GaN targets in an $\mathrm{N}_{2}$ or $\mathrm{N}_{2} / \mathrm{Ar}$ atmosphere. ${ }^{1-6}$ Sputtering is attractive because of its convenience and low cost. Several reports have indicated that the incorporation of hydrogen during GaN growth is highly desirable. ${ }^{7-9}$ Hydrogen is thought to passivate dangling bonds, dislocations, and defects in amorphous and polycrystalline materials, just as it does in $a-\mathrm{Si}: \mathrm{H}$. Hydrogenation of $\mathrm{GaN}$ during growth by remote-plasma metal-organic chemical-vapor deposition at $380{ }^{\circ} \mathrm{C}$ has made it possible to fabricate visible-blind photodiodes ${ }^{10}$ and light-emitting devices. ${ }^{11}$ The addition of $\mathrm{H}_{2}$ during the growth of both single-crystal ${ }^{9}$ and disordered materials ${ }^{8}$ has been observed to increase the intensity of the photoluminescence (PL) significantly. In the latter case, the material was grown in a similar manner to that reported here, but using magnetron sputtering and no Ar, and the optical properties were examined. This paper discusses the changes in the optical and electrical properties with hydrogenation.

GaN films were deposited using a Nordiko, $13.56 \mathrm{MHz}$ conventional rf sputtering system. The Ga target is contained in a $\mathrm{Ni}$ dish on the lower driven electrode, and substrates are attached to the upperearthed electrode. $\mathrm{Ar}, \mathrm{N}_{2}$, and $\mathrm{H}_{2}$ are fed into the chamber via mass-flow controllers. A quartz shield surrounds the area between the two electrodes to confine the plasma. Both electrodes are water cooled, keeping the substrate temperature near room temperature. Prior to each deposition, the chamber and gas lines are evacuated to below $3 \times 10^{-4} \mathrm{~Pa}$. The $\mathrm{N}_{2}$ and Ar flow rates were 8 and $12 \mathrm{SCCM}$ (standard cubic centimeter per minute), respectively. The target bias was $-800 \mathrm{~V}$ and the pressure was $2.0 \mathrm{~Pa}$. The $\mathrm{H}_{2}$ flow rate was varied in the range of 0-5 SCCM, and the film thickness was kept close to $100 \mathrm{~nm}$.

Ellipsometry at $632.8 \mathrm{~nm}$ was used to measure the film thickness and refractive index. The surface was imaged using

\footnotetext{
${ }^{a)}$ Electronic mail: s.henley@eim.surrey.ac.uk

${ }^{b)}$ Electronic mail: s.silva@surrey.ac.uk
}

a Hitachi S4000 scanning electron microscope (SEM). The surface topography was analyzed using a Digital Instruments, Dimension 3100 atomic force microscope (AFM) operating in tapping mode. The relative elemental composition of the films was measured using energy-dispersive $\mathrm{x}$-ray (EDX) spectroscopy in a Philips XL30 SEM. The opticalabsorption spectra of samples on quartz substrates were measured with a Camspec M300 UV-visible spectrophotometer. The absorption spectra of the films were obtained by subtracting the substrate absorbance from the total absorbance. Optical band gaps were estimated by extrapolating linear fits to plots of the absorption coefficient $\alpha$ squared versus the photon energy $h \nu$ at the band edge. A Nicolet Protégé 460 Fourier transform spectrometer was used to obtain infrared (IR) transmission spectra from the films on Si. PL spectra were obtained at room temperature using a Renishaw microRaman system and a $325 \mathrm{~nm}$ excitation. $I-V$ measurements were performed on metal-semiconductor-metal (MSM) structures, and differential resistivity values were calculated from fits to the data at $\pm 0.5 \mathrm{~V}$. The structures were fabricated by evaporating $0.35-\mathrm{mm}$-diam $\mathrm{Al}$ pads onto the films on $\mathrm{Cr}$ on-glass substrates.

A selection of the IR spectra of films deposited at different $\mathrm{H}_{2}$ concentrations is plotted in Fig. 1(a). As the $\mathrm{H}_{2}$ flow rate is increased, a broad peak emerges at around $3205 \mathrm{~cm}^{-1}$ and increases monotonically with $\mathrm{H}_{2}$ concentration. This is thought to be the $\mathrm{N}-\mathrm{H}$ stretching mode which has been reported at $3200 \mathrm{~cm}^{-17}$. There is also a very small peak at around $2100 \mathrm{~cm}^{-1}$ which reaches a maximum at $4.8 \% \mathrm{H}_{2}$ and has previously been attributed to the $\mathrm{Ga}-\mathrm{H}$ stretching mode. ${ }^{7}$ Thus, as expected, the degree of hydrogenation increases with $\mathrm{H}_{2}$ flow rate.

In Fig. 1(b), the oxygen content increases rapidly with $\mathrm{H}_{2}$ concentration, from 3 at. $\%$ at $0 \% \mathrm{H}_{2}$ to 21 at. $\%$ at $7 \%$ $\mathrm{H}_{2}$. Thereafter, it decreases slightly to around 18 at. $\%$ at $20 \% \mathrm{H}_{2}$. Since there is no obvious change in the deposition rate, two possible reasons are considered. One possibility is that the hydrogen supply was contaminated with $\mathrm{O}_{2}$ or $\mathrm{H}_{2} \mathrm{O}$. However, this is unlikely because the purity was $99.9995 \%$, and this would not explain the levelling off at higher $\mathrm{H}_{2}$ flow 


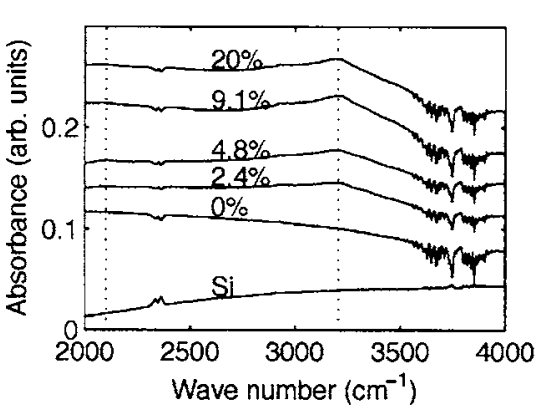

(a)

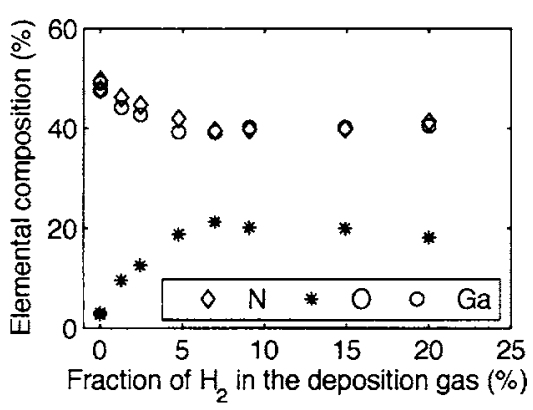

(b) rates. The $\mathrm{H}_{2}$ may also increase the amount of $\mathrm{O}$ adsorbed onto the growth surface. However, significant $\mathrm{O}$ contamination is not uncommon for sputtered GaN. ${ }^{12-14}$

The PL spectra of the $100 \mathrm{~nm}$ films are plotted in Fig. 2(a). The $0 \% \mathrm{H}_{2}$ sample exhibits essentially no PL, but a broad peak centered at around $2.1-2.2 \mathrm{eV}$ emerges and increases in amplitude with increased $\mathrm{H}_{2}$ flow. There is also a small peak at $3.3 \mathrm{eV}$, possibly corresponding to band-toband transitions, although this could be the overtone of the Raman scattering from the hydrogen stretch mode. The sharp peaks at higher energies are the GaN $A_{1}$ (LO) Raman peak and its harmonics. The PL spectra of the $1 \mu \mathrm{m}$ samples are shown in Fig. 2(b). In the range of $1.95-2.30 \mathrm{eV}$, the hydrogenated sample exhibits luminescence in a broad band, consisting of two overlapping peaks centered at 1.99 and $2.13 \mathrm{eV}$. The trends in the PL intensity are different from those observed by Miyazaki et al. ${ }^{8}$ There, PL was only observed below $100 \mathrm{~K}$ without hydrogenation and in a broad band at $1.9-3.3 \mathrm{eV}$. Hydrogenation gave rise to a single room-temperature luminescence peak at $3.25 \mathrm{eV}$.Figure 2(c) shows a plot of the width of the $A_{1}$ (LO) Raman peak as a function of the hydrogen concentration in the deposition atmosphere. The observed increase in the peak width, as the hydrogen concentration is raised, is indicative of a decrease in the long-range order of the films, most likely due to a decrease in the grain size. Despite the apparent increase in structural disorder (discussed more fully later), the hydrogen may terminate dangling bonds and thus reduce the concentration of sites where nonradiative recombination can take place, improving the PL, albeit in the yellow-band region. Yellow luminescence is regularly observed for undoped or $n$-type $\mathrm{GaN}$ at around $2.2 \mathrm{eV}$ and has been attributed to the radiative recombination of donor-acceptor pairs created by point or extended crystalline defects. ${ }^{15,16}$

As the deposition $\mathrm{H}_{2}$ fraction increases from $0 \%$ to $20 \%$, the refractive index decreases from 2.45 to 1.98 , and the band gap increases from 3.06 to $3.64 \mathrm{eV}$, these are thought mainly to reflect the increase in the films' oxygen content. This is because the changes have been found to be correlated with $\mathrm{O}$ contamination for other nonhydrogenated films.

In Fig. 3, the trends in the resistivity data are very different from those of the other parameters. There is an initial rapid decrease from around $2 \times 10^{8} \Omega \mathrm{cm}$ at $0 \% \mathrm{H}_{2}$ to a minimum of $2 \times 10^{6} \Omega \mathrm{cm}$ at $2.4 \% \mathrm{H}_{2}$. Thereafter, it increases again, rapidly at first, reaching $8 \times 10^{11} \Omega \mathrm{cm}$ at $20 \%$ $\mathrm{H}_{2}$. This could be due to the hydrogen initially passivating defects in the intergranular regions, easing the passage of current between crystallites. Passivation of defect states at the $\mathrm{Cr}-\mathrm{GaN}$ interface could account for the emergence of the Schottky barrier ${ }^{17}$ which is visible as a difference in the
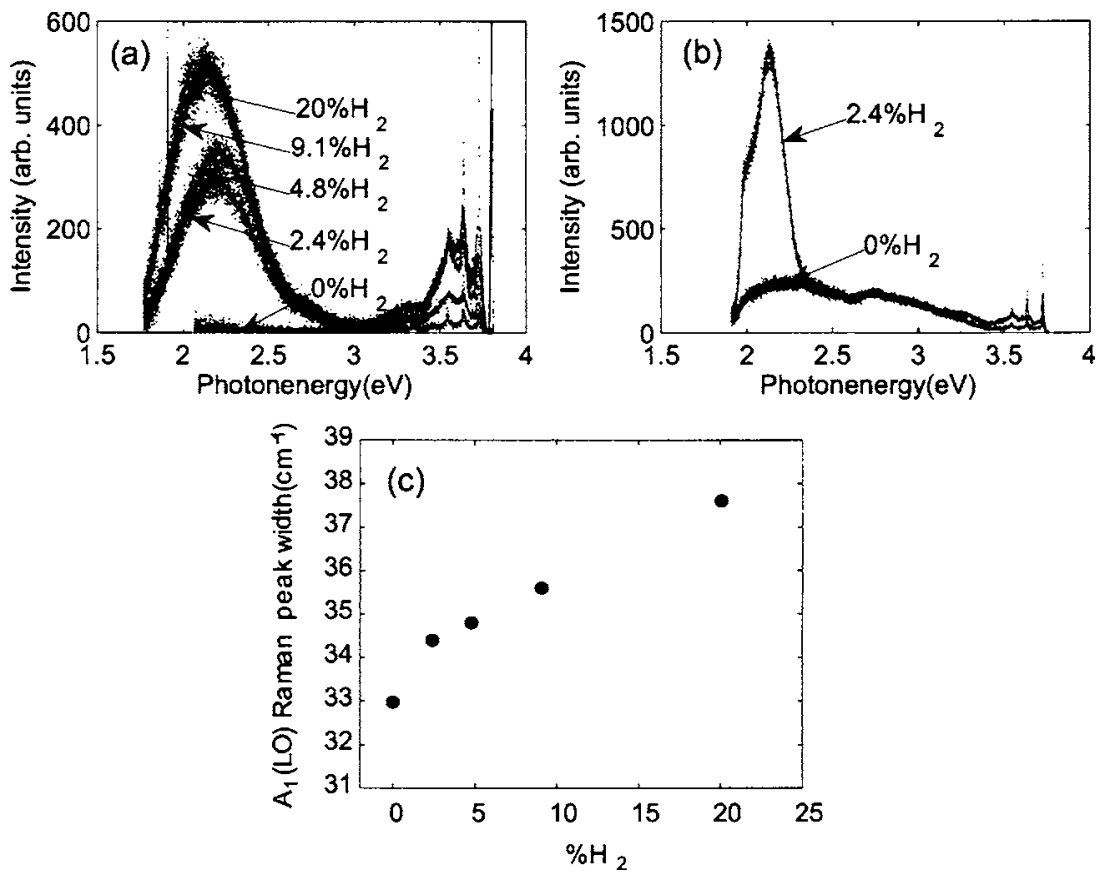

FIG. 2. Room-temperature PL spectra of (a) $100 \mathrm{~nm}$ and (b) $1 \mu \mathrm{m}$ films for different $\mathrm{H}_{2}$ deposition fractions, (c) Plot of $A_{1}$ (LO) phonon peak width as a function of the hydrogen concentration in the deposition atmosphere. 


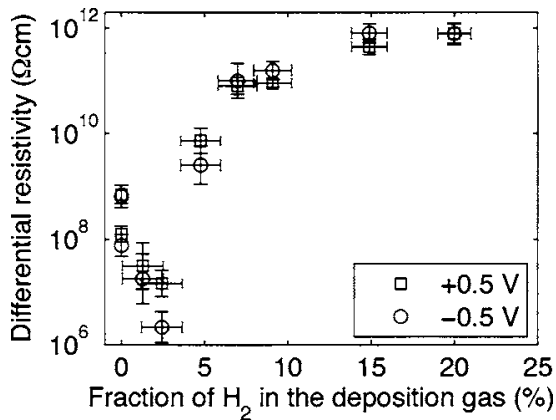

FIG. 3. Differential resistivity as a function of the hydrogen concentration in the deposition atmosphere.

resistivities at +0.5 and $0.5 \mathrm{~V}$. Beyond this point, increased passivation of defects may reduce the traps necessary for Poole-Frenkel conduction (which takes place for $0 \% \mathrm{H}_{2}$, according to the $I-V$ characteristics). The Schottky barrier may then cease to be visible because the high resistivity makes the dominant conduction mechanism bulk limited. Alternatively, the minimum in the resistivity could indicate a region in which crystallites reach the back contact rather than form after an initial amorphous region. However, AFM and SEM images appear to show reduced crystallinity with $\mathrm{H}_{2}$ flow. The widths of the GaN $A_{1}$ (LO) Raman peaks also increase monotonically with $\mathrm{H}_{2}$ flow rate (from $33.0 \mathrm{~cm}^{-1}$ at $0 \% \mathrm{H}_{2}$ to $37.6 \mathrm{~cm}^{-1}$ at $20 \% \mathrm{H}_{2}$ ), indicative of an increased structural disorder. This may also contribute towards the resistivity increase.

Figure 4 shows AFM phase and SEM images of the surfaces of $1 \mu \mathrm{m}$ films deposited at $0 \%$ and $2.4 \% \mathrm{H}_{2}$. In the hydrogenated film, particles appear as loose clumps rather than as well-defined grains, and the AFM phase image appears to show large numbers of crystallites within each clump. It is as though there has been repeated nucleations during the growth process. This would be consistent with a film which does not become more ordered with film thickness, rather than with the type observed without $\mathrm{H}_{2}$, where columnar crystallites increase in size with film thickness. Miyazaki et al. observed that films sputtered with $\mathrm{H}_{2}$ become amorphouslike. ${ }^{8}$ The surfaces of the $100 \mathrm{~nm}$ films become increasingly rough with $\mathrm{H}_{2}$ flow, but there is nothing obvious to explain the resistivity minimum at $2.4 \% \mathrm{H}_{2}$.

In conclusion, hydrogenation of the film by the addition of $\mathrm{H}_{2}$ during growth increases the PL from essentially zero to a weak but clear signal, albeit in the yellow-band region. This occurs together with an apparent increase in the degree of structural disorder. The resistivity reaches a minimum at $2.4 \% \mathrm{H}_{2}$. The increased $\mathrm{O}$ contamination decreases the re-
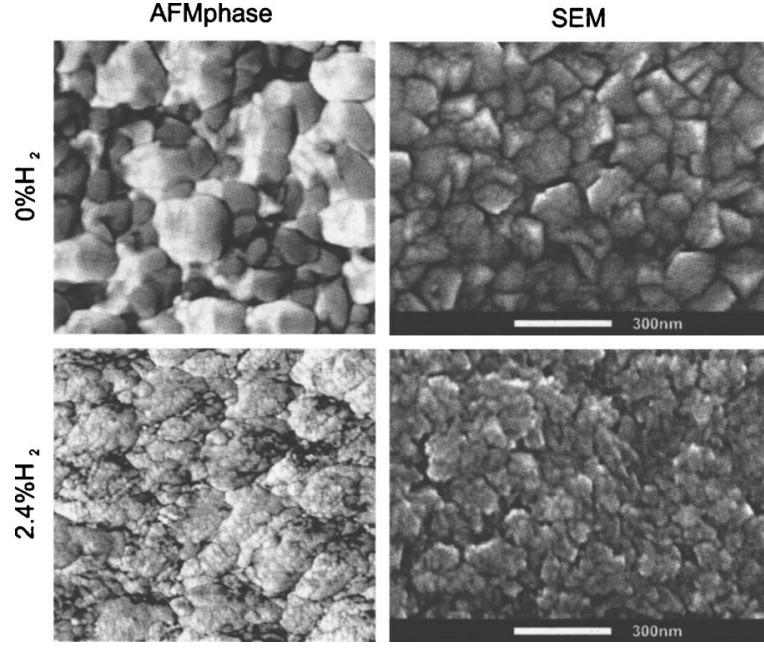

FIG. 4. AFM phase and SEM images of the surfaces of $1 \mu \mathrm{m}$ films deposited at $0 \%$ and $2.4 \% \mathrm{H}_{2}$. All scales are the same.

fractive indices and increases the band-gap values. Hydrogenation may allow GaN sputtered at low temperatures to be used for device applications such as transparent thin-film transistors and UV photodiodes.

The authors would like to thank C. Giusca for AFM imaging.

${ }^{1}$ H. J. Hovel and J. J. Cuomo, Appl. Phys. Lett. 20, 71 (1972).

${ }^{2}$ E. Lakshmi, B. Mathur, A. B. Bhattacharya, and V. P. Bhargava, Thin Solid Films 74, 77 (1980)

${ }^{3}$ S. Nonomura, S. Kobayashi, T. Gotoh, S. Hirata, T. Ohmori, T. Itoh, S. Nitta, and K. Morigaki, J. Non-Cryst. Solids 198-200, 174 (1996).

${ }^{4}$ V. Bondar, I. Kucharsky, B. Simkiv, L. Akselrud, V. Davydov, Y. Dubov, and S. Popovich, Phys. Status Solidi A 176, 329 (1999).

${ }^{5}$ W. T. Young, S. R. P. Silva, M. Benyoucef, M. Kuball, J. V. Anguita, J. M. Shannon, K. P. Homewood, and B. J. Sealy, Phys. Status Solidi A 176, 319 (1999).

${ }^{6}$ T. Miyazaki, T. Fujimaki, and S. Adachi, J. Appl. Phys. 89, 8316 (2001).

${ }^{7}$ S. Yagi, Jpn. J. Appl. Phys., Part 2 38, L792 (1999).

${ }^{8}$ T. Miyazaki, K. Takada, S. Adachi, and K. Ohtsuka, J. Appl. Phys. 97, 093516 (2005).

${ }^{9}$ D. Lancefield (private communication).

${ }^{10}$ S. Yagi, Appl. Phys. Lett. 76, 345 (2000).

${ }^{11}$ S. Yagi, S. Suzuki, and T. Iwanaga, Jpn. J. Appl. Phys., Part 2 40, L1349 (2001).

${ }^{12}$ K. Abe, J. Non-Cryst. Solids 227-230, 1096 (1998).

${ }^{13}$ W. T. Young, S. R. P. Silva, J. V. Anguita, J. M. Shannon, K. P. Homewood, and B. J. Sealy, Diamond Relat. Mater. 9, 456 (2000).

${ }^{14}$ V. Prajzler, I. Hüttel, J. Špirková, V. Machovič, J. Schröfel, V. Peřina, and J. Hamáček, The Second International Conference on Technological Advances of Thin Films, Singapore, 13-17 July 2004 (unpublised).

${ }^{15}$ F. A. Ponce, D. P. Bour, and W. Götz, Appl. Phys. Lett. 68, 57 (1996).

${ }^{16}$ V. Bondar, Phys. Status Solidi A 176, 635 (1999).

${ }^{17}$ S. N. Mohammad, J. Appl. Phys. 97, 063703 (2005). 